\title{
Avaliação da formulação de reativos à base de ácido pícrico visando a revelação do grão austenítico prévio em diferentes tipos de aços
}

\author{
Natália Aparecida Barbosa Pimenta \\ Paulo Sérgio Moreira ${ }^{1}$ \\ Geraldo Lúcio de Faria ${ }^{1 *}$ (D)
}

\section{Resumo}

As técnicas de revelação dos contornos de grãos austeníticos prévios em aços são importantes ferramentas de caracterização. O método mais usual faz uso de reativos à base de ácido pícrico, que, na maioria dos casos, não produz resultados satisfatórios. Diante disso, foram investigadas, neste trabalho, formulações de reativos à base de ácido pícrico, variando-se a concentração de ácido clorídrico, com o objetivo de propor condições de ataque eficientes para sete aços fabricados no Brasil. Para cada aço, foram avaliados reativos com cinco concentrações distintas de $\mathrm{HCl}$ e diferentes tempos de ataque. Foi possível revelar os contornos de grãos austeníticos eficientemente para todos os tipos de aços estudados adequando-se a concentração de $\mathrm{HCl}$ adicionado e o tempo de ataque. Com base nos resultados alcançados, foi possível disponibilizar uma tabela e uma equação de regressão linear múltipla que apresenta o tempo de ataque em função do carbono equivalente do aço e da concentração de $\mathrm{HCl}$. Concluiu-se que a concentração de HCL utilizada no reativo é o parâmetro que exerce maior influência sobre o tempo de ataque.

Palavras-chave: Grão austenítico prévio; Ácido pícrico; Ácido clorídrico; Carbono equivalente.

\section{Evaluation of picric acid etchant formulations for the prior austenite grain revelation in different steel types}

\begin{abstract}
Techniques used to reveal the prior austenite grain boundaries in steels are important characterization tools. The most common method used to reveal the austenite grain boundaries is with picric acid based etchant. Unfortunately, it does not produce satisfactory results in most cases. Therefore, in the present study, the formulation of picric acid-based etchant was investigated. Five hydrochloric acid concentration at different etching time were studied in order to determine what would be the most efficient etching condition for seven types of steels currently manufactured in Brazil. It was possible to reveal the austenite grain boundaries efficiently for all studied steels by adjusting the hydrochloric acid concentration and the etching time. Based on the achieved results, it was possible to make available a reference table and a multiple linear regression equation that highlight the optimal etching time as a function of the carbon equivalent and $\mathrm{HCl}$ concentration. It was concluded that the used $\mathrm{HCl}$ concentration is the parameter which has the greater influence on the etching time.
\end{abstract}

Keywords: Prior austenite grain; Picric acid; Hydrochloric acid; Carbon equivalent.

\section{Introdução}

As técnicas para revelação de grãos austeníticos prévios em aços com diferentes composições químicas e microestruturas mostram-se cada vez mais importantes para o desenvolvimento de novos produtos [1-5]. Entretanto, este processo pode se tornar muito complexo quando empregado em determinados tipos de aços [6].
Existem vários métodos indiretos para se revelar os grãos austeníticos prévios, entre eles, destacam-se as técnicas de revelação por meio de ataque térmico, ataque por oxidação e ataque químico [5-9]. O ataque térmico consiste em aquecer uma amostra com superfície devidamente plana, em atmosfera inerte, até a temperatura de austenitização e

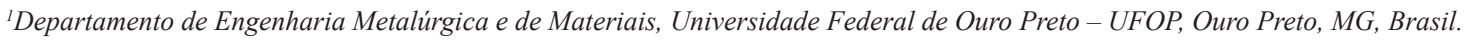

*Autor correspondente: geraldolfaria@yahoo.com.br
} 
mantê-la por tempo suficiente para que sulcos se formem em sua superfície, nos locais onde há interseções dos contornos de grão da austenita [6]. Este método pode propiciar bons resultados, porém, há relatos de aparecimento de traços fantasmas, tornando-o impreciso [7]. O método de ataque por oxidação baseia-se em aquecer uma amostra com superfície pré-polida até a temperatura de austenitização, em uma atmosfera com baixa pressão parcial de oxigênio. A oxidação preferencial dos contornos de grãos austeníticos criará contraste direto para a técnica de microscopia óptica [6-9]. Entretanto, uma desvantagem deste método é a dificuldade experimental em estabelecer uma atmosfera bem controlada, exigindo para esse fim, uma infraestrutura que não é comum em laboratórios de caracterização microestrutural [9].

A técnica de ataque químico mais utilizada em todo o mundo, baseia-se no uso de uma solução aquosa saturada em ácido pícrico combinada com $\mathrm{HCl}$ e um agente umectante [6,9]. Durante a austenitização de aços, alguns elementos como o $\mathrm{P}, \mathrm{Si}, \mathrm{Cr}, \mathrm{Ti}, \mathrm{Nb}$ podem se segregar nos contornos de grãos austeníticos. Caso os aços sejam temperados, essas regiões de segregação terão potenciais químicos diferentes da matriz martesítica homogênea [9-12]. Nesse cenário, o princípio da técnica consiste em revelar os grãos austeníticos prévios por meio da utilização de uma solução que seja sensível às pequenas diferenças de potencial químico. Deseja-se que o reativo promova um ataque preferencial nas regiões de segregação, revelando indiretamente onde estavam os contornos de grãos austeníticos [5].

Apesar da técnica de ataque químico com solução aquosa saturada em ácido pícrico ser a mais utilizada na indústria e na academia, diversos autores [5-9] relatam dificuldades ao tentarem utilizá-la em alguns tipos de aços. Alguns autores relatam que conseguem maior eficiência do método somente quando o aplicam em aços médio e alto carbono, não alcançando resultados satisfatórios em aços baixo carbono $[9,13]$. Outros destacam que aços com teores mais significativos de $\mathrm{Cr}$, Si e P são eficientemente atacados, mas aços comuns não [6,9]. Alguns trabalhos disponíveis na literatura $[6,9,14]$ ainda discutem que, mesmo em aços médio e alto carbono com adição de elementos de liga, algumas vezes, o método não é eficiente em decorrência do que eles chamam de superataque. De acordo com esses estudos, a solução utilizada é quimicamente agressiva para o material atacado e, mesmo para curtos intervalos de tempo de ataque, acontece um intenso processo de corrosão superficial, impossibilitando a geração de contraste para a revelação dos grãos austeníticos.

Ao se observar trabalhos publicados na literatura [6,9,14], assim como relatos diversos da indústria, nota-se que muitas vezes eles são divergentes. Enquanto alguns autores relatam resultados positivos em relação à eficiência do ataque químico para uma determinada classe de aços, outros relatam experiências negativas para a mesma classe $[9,14]$. Segundo Reiter et al. [14], isso poderia estar associado à utilização de formulações inadequadas do reativo à base de ácido pícrico. Esses autores afirmam que pequenas variações na concentração de $\mathrm{HCl}$ no reativo podem implicar no sucesso, ou insucesso da técnica para uma mesma classe de aços, principalmente tendo em vista que parece haver uma grande influência desse parâmetro no tempo de ataque, apesar dos autores não apresentarem evidências quantitativas disso.

Diante do exposto, foram avaliados, neste trabalho, diferentes formulações do reativo à base de ácido pícrico, variando-se a sua concentração de $\mathrm{HCl}$, para vários tempos de ataque, visando determinar a condição mais eficiente de ataque em sete aços atualmente fabricados no Brasil. Esse artigo disponibiliza uma tabela e uma equação de regressão linear múltipla que apresenta o tempo ideal de ataque em função do carbono equivalente do aço e da concentração de $\mathrm{HCl}$ mais recomendada.

\section{Materiais e métodos}

\subsection{Materiais}

Para o desenvolvimento desse estudo, foram utilizados sete aços distintos, possibilitando o estudo de materiais com diferentes valores de carbono equivalente. Na Tabela 1 são apresentas as composições químicas dos aços, determinadas por meio da técnica de espectrometria de emissão óptica (Oxford Instruments, modelo Foundry-Master Xpert ${ }^{\circledR}$ ). Também são apresentados os valores de carbono equivalente de cada aço, calculados por meio da Equação 1 [15].

Tabela 1. Composição química dos aços estudados (\% em massa) e respectivos valores de carbono equivalente

\begin{tabular}{|c|c|c|c|c|c|c|c|c|c|c|c|c|}
\hline \multirow{2}{*}{ AÇO } & \multirow{2}{*}{ C.E.* } & \multicolumn{11}{|c|}{ ELEMENTO } \\
\hline & & $\mathrm{C}$ & $\mathbf{S i}$ & Mn & $\mathbf{P}$ & $\mathbf{S}$ & $\mathrm{Cr}$ & Mo & $\mathbf{N i}$ & $\mathbf{N b}$ & $\mathbf{T i}$ & $\mathbf{V}$ \\
\hline A & 0,274 & 0,156 & 0,160 & 0,611 & 0,020 & 0,026 & 0,029 & 0,013 & 0,025 & 0,005 & 0,001 & 0,003 \\
\hline B & 0,495 & 0,097 & 0,281 & 0,951 & 0,022 & 0,003 & 0,601 & 0,581 & 0,017 & 0,010 & 0,022 & 0,041 \\
\hline $\mathrm{C}$ & 0,504 & 0,190 & 0,288 & 0,865 & 0,025 & 0,027 & 0,056 & 0,246 & 1,610 & 0,003 & 0,002 & 0,005 \\
\hline $\mathrm{D}$ & 0,598 & 0,469 & 0,234 & 0,700 & 0,020 & 0,015 & 0,028 & 0,019 & 0,018 & 0,004 & 0,001 & 0,002 \\
\hline $\mathrm{E}$ & 0,692 & 0,438 & 0,253 & 1,740 & 0,025 & 0,006 & 0,006 & 0,026 & 0,011 & 0,003 & 0,001 & 0,002 \\
\hline F & 0,828 & 0,411 & 0,273 & 0,703 & 0,030 & 0,012 & 0,711 & 0,224 & 1,640 & 0,008 & 0,003 & 0,006 \\
\hline $\mathrm{G}$ & 1,037 & 0,890 & 0,236 & 0,677 & 0,019 & 0,013 & 0,169 & 0,012 & 0,016 & 0,006 & 0,001 & 0,002 \\
\hline
\end{tabular}

*Abreviação: Carbono Equivalente. 


$$
C . E .=C+\frac{M n}{6}+\frac{C r+M o+V}{5}+\frac{N i+C u}{15}
$$

\subsection{Procedimento experimental}

\subsubsection{Tratamento térmico}

Todas as amostras foram tratadas termicamente com o intuito de se obter microestruturas majoritariamente martensíticas, o que é fundamental para a eficiência do ataque químico com reativo à base de ácido pícrico, conforme já citado na introdução [9-12]. Neste trabalho, elas foram aquecidas até $1000^{\circ} \mathrm{C}$, permanecendo nessa temperatura por 40 minutos para a completa austenitização. Em seguida, todas as amostras foram resfriadas em água à temperatura ambiente, realizando-se, desta forma, o tratamento térmico de têmpera. Todas as amostras foram metalograficamente preparadas seguindo as recomendações da norma ASTM E3 [16] e atacadas com as diferentes formulações do reativo à base de ácido pícrico.

\subsubsection{Ataque químico com reativo à base de ácido pícrico}

A base do reativo químico utilizada para o ataque foi composta por $3 \mathrm{~g}$ de ácido pícrico, $240 \mathrm{~mL}$ de água destilada e 10 gotas de detergente neutro.
O ácido clorídrico foi adicionado em cinco diferentes quantidades: $0,5 \mathrm{~mL}, 1,0 \mathrm{~mL}, 1,5 \mathrm{~mL}, 2,0 \mathrm{~mL}$ e $2,5 \mathrm{~mL}$. Para cada concentração de ácido clorídrico, cada um dos aços foi submetido a diferentes intervalos de tempo de ataque e aquele que proporcionou o melhor resultado foi verificado. A evolução de contraste dos ataques em função da concentração de ácido clorídrico e do tempo foi avaliada por meio de imagens de microscopia óptica, utilizando-se o equipamento da marca LEICA, modelo DM2700M. Estipulou-se que a concentração de $\mathrm{HCl}$ mais eficiente foi aquela com a qual os grãos austeníticos prévios foram revelados com maior nitidez, no menor intervalo de tempo de ataque e com a menor ocorrência de pites de corrosão.

\section{Resultados e discussão}

\subsection{Avaliação das micrografias obtidas para cada condição de ataque}

A Figura 1 apresenta os resultados obtidos para o aço "A", baixo carbono, da classe de aços ABNT 1015. Observa-se que o reativo com $1,0 \mathrm{~mL}$ de ácido clorídrico, com tempo de ataque de 120 s, foi o que revelou os contornos de grãos prévios da austenita sem significativa ocorrência de pites de corrosão. Para maiores concentrações de $\mathrm{HCl}$, percebe-se a presença significativa de pites de corrosão. Destaca-se

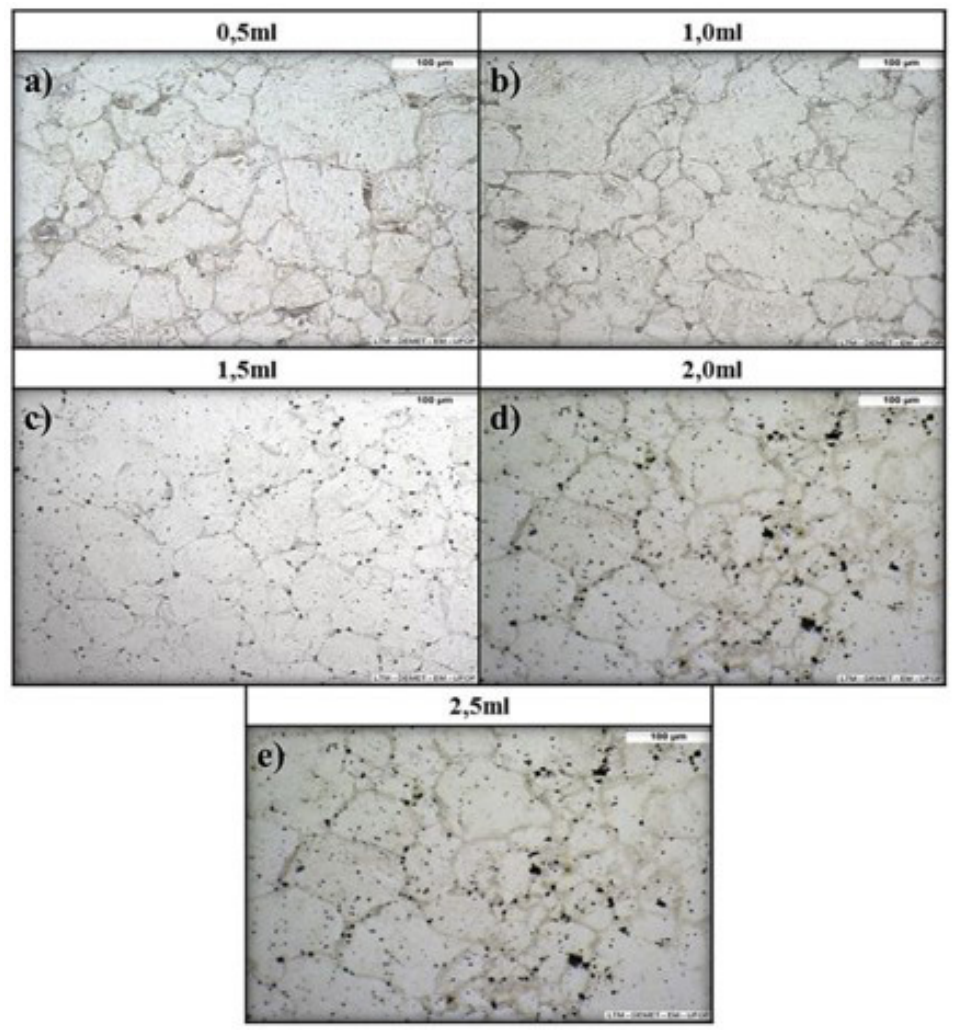

Figura 1. Micrografias resultantes do aço A com carbono equivalente igual a 0,27 atacado nas condições de: (a) $0,5 \mathrm{~mL}$ de $\mathrm{HCl}$ e tempo de 180 s; (b) $1,0 \mathrm{~mL}$ de $\mathrm{HCl}$ e tempo de $120 \mathrm{~s}$; (c) $1,5 \mathrm{~mL}$ de $\mathrm{HCl}$ e tempo de $60 \mathrm{~s}$; (d) $2,0 \mathrm{~mL}$ de $\mathrm{HCl}$ e tempo de $50 \mathrm{~s}$; (e) $2,5 \mathrm{~mL}$ de $\mathrm{HCl}$ e tempo de $20 \mathrm{~s}$. 
que por se tratar de um aço com baixa temperabilidade, ao ser temperado em água, houve tempo para a formação de constituintes difusionais nos contornos de grãos austeníticos, os quais foram preferencialmente atacados pelo reativo, criando um contraste favorável para a técnica [9].

As micrografias do aço "B" estão apresentadas na Figura 2. A melhor condição de ataque foi com 1,5mL de $\mathrm{HCl}$ (60 segundos). Esse aço pode ser classificado como um aço de alta resistência baixa liga, comumente empregado na indústria naval [17]. Ele possui adições de $\mathrm{Cr}$ e Mo que são bons formadores de carbonetos. Além da possível segregação de elementos nos contornos de grão austenítico, a precipitação preferencial de carbonetos também pode ter contribuído para o ataque seletivo [17].

A Figura 3 apresenta as micrografias referentes ao aço “C”, que pertence à classe de aços ABNT 8620 (VB20) [18]. A quantidade de ácido clorídrico que resultou na melhor condição de revelação foi a de 1,5mL (60s). Na Figura 4 são apresentados os resultados obtidos para o aço "D" que pode ser classificado como um clássico ABNT 1045 [7]. Pôde-se

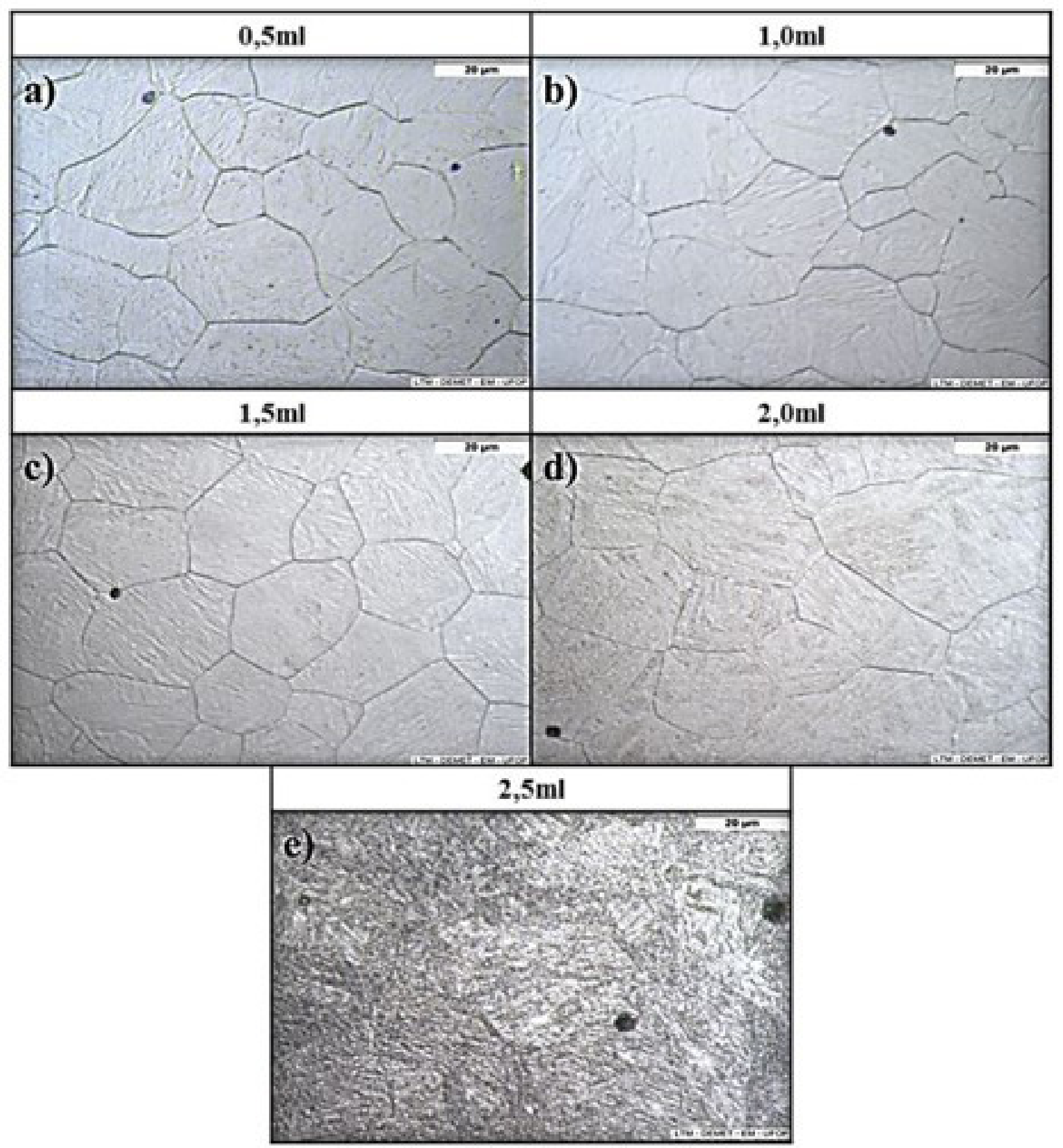

Figura 2. Micrografias resultantes do aço B com carbono equivalente igual a 0,50 atacado nas condições de: (a) $0,5 \mathrm{~mL}$ de $\mathrm{HCl}$ e tempo de $600 \mathrm{~s}$; (b) $1,0 \mathrm{~mL}$ de $\mathrm{HCl}$ e tempo de $150 \mathrm{~s}$; (c) $1,5 \mathrm{~mL}$ de $\mathrm{HCl}$ e tempo de $60 \mathrm{~s}$; (d) $2,0 \mathrm{~mL}$ de $\mathrm{HCl}$ e tempo de $35 \mathrm{~s}$; (e) 2,5 de $\mathrm{Hcl}$ e tempo de $15 \mathrm{~s}$. 
concluir que a condição com $1,0 \mathrm{~mL}$ de ácido clorídrico e 180 s de ataque foi a melhor. Por se tratar de um aço médio carbono de média temperabilidade, acredita-se que os principais mecanismos de contraste estejam relacionados com formação de constituintes difusionais associado à segregação química nos contornos de grãos austeníticos [7].

A Figura 5 ilustra resultados obtidos para o aço "E", que se enquadra na classe ABNT 1345. Para este aço, a condição de ataque mais eficiente foi $1,5 \mathrm{~mL}$ de $\mathrm{HCl}$ (30s). O Aço ABNT1345 possui algumas semelhanças químicas com o aço ABNT 1045, no entanto sua concentração de Mn é maior, o que aumenta a sua temperabilidade. Apesar disso, os mecanismos de contraste de ambos foram semelhantes, ou seja, formação de pequena fração de constituintes difusionais nos contornos de grãos austeníticos promovendo ataque preferencial. As fotomicrografias resultantes dos ataques realizados no aço "F" são apresentadas na Figura 6. Para este tipo de aço (ABNT 4340 - VM40), a quantidade ideal de ácido clorídrico que revelou de forma mais eficiente os grãos austeníticos prévios foi $1,0 \mathrm{~mL}(180 \mathrm{~s})$. Por fim, são

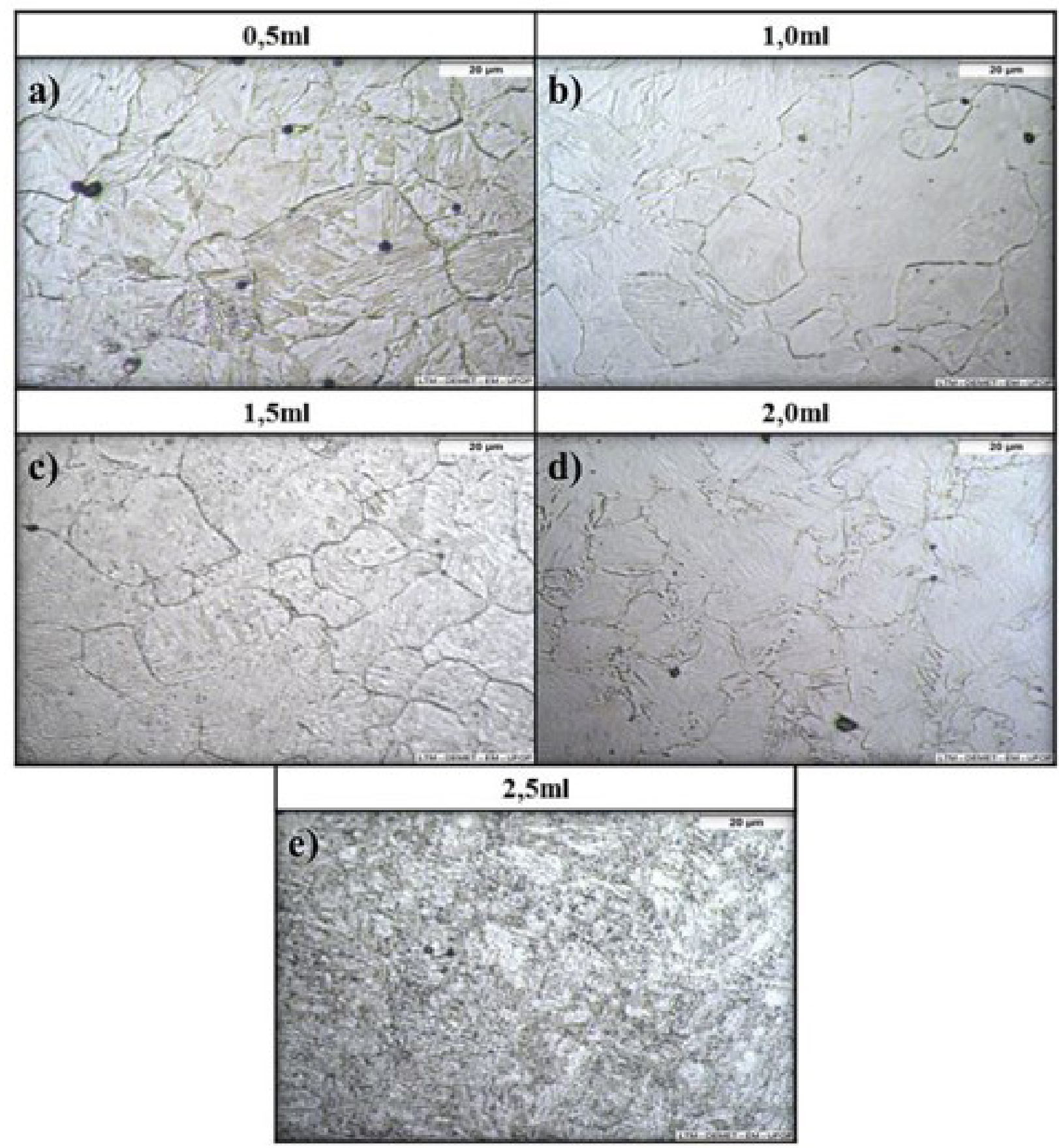

Figura 3. Micrografias resultantes do aço $\mathrm{C}$ com carbono equivalente igual a 0,50 atacado nas condições de: (a) $0,5 \mathrm{~mL}$ de $\mathrm{HCl}$ e tempo de $250 \mathrm{~s}$; (b) $1,0 \mathrm{~mL}$ de $\mathrm{HCl}$ e tempo de $180 \mathrm{~s}$; (c) $1,5 \mathrm{~mL}$ de $\mathrm{HCl}$ e tempo de $60 \mathrm{~s}$; (d) $2,0 \mathrm{~mL}$ de $\mathrm{HCl}$ e tempo de $25 \mathrm{~s}$; (e) 2,5 de $\mathrm{HCl}$ e tempo de $15 \mathrm{~s}$. 


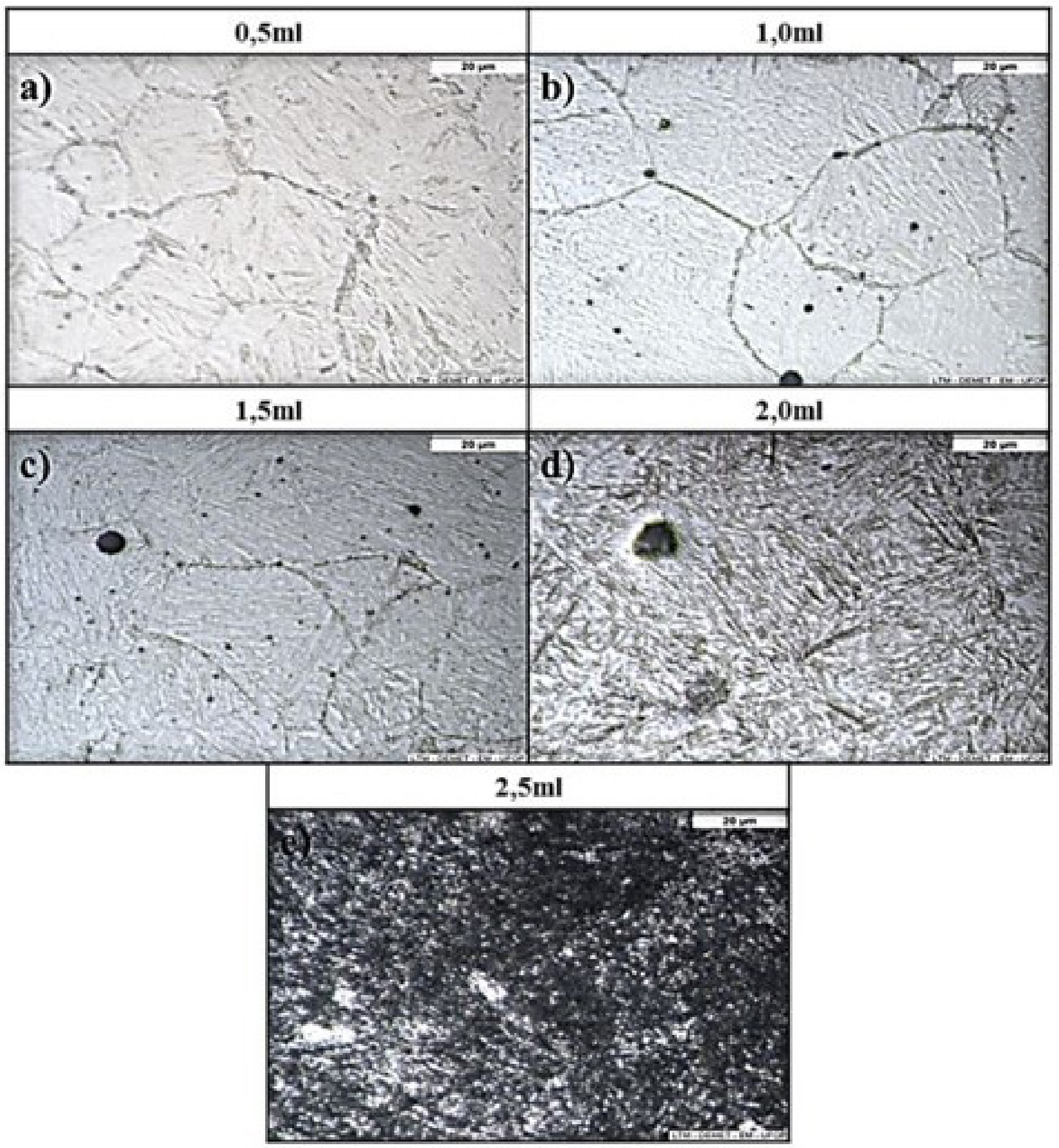

Figura 4. Micrografias resultantes do aço D com carbono equivalente igual a 0,60 atacado nas condições de: (a) $0,5 \mathrm{~mL}$ de $\mathrm{HCl}$ e tempo de $210 \mathrm{~s}$; (b) $1,0 \mathrm{~mL}$ de $\mathrm{HCl}$ e tempo de $180 \mathrm{~s}$; (c) $1,5 \mathrm{~mL}$ de $\mathrm{HCl}$ e tempo de $180 \mathrm{~s}$; (d) $2,0 \mathrm{~mL}$ de $\mathrm{HCl}$ e tempo de $20 \mathrm{~s}$; (e) $2,5 \mathrm{~mL}$ de $\mathrm{HCl}$ e tempo de $10 \mathrm{~s}$.

apresentadas na Figura 7 as micrografias obtidas para o aço "H", que atende à classe de aços Eutetóides de aplicação ferroviária. Para esse aço, a melhor condição foi $1,5 \mathrm{~mL}$ de $\mathrm{HCl}(60 \mathrm{~s})$.

A Tabela 2 apresenta de forma resumida as condições ótimas de ataque para se revelar os contornos de grãos austeníticos prévios dos aços estudados, atendo-se aos parâmetros principais deste estudo, que são: a concentração ideal de ácido clorídrico, o tempo de ataque e o carbono equivalente dos aços estudados. Diante dos resultados obtidos, pôde-se notar uma tendência das quantidades de ácido clorídrico mais favoráveis para revelação eficiente dos grãos austeníticos prévios estarem entre $1,0 \mathrm{~mL}$ e $1,5 \mathrm{~mL}$.

Percebeu-se ainda que o tempo de ataque é uma variável importante para a eficiência do procedimento. Os melhores intervalos de tempo de ataque claramente dependem da composição química do aço e da concentração de ácido clorídrico utilizada no reativo, podendo ser esse um dos 


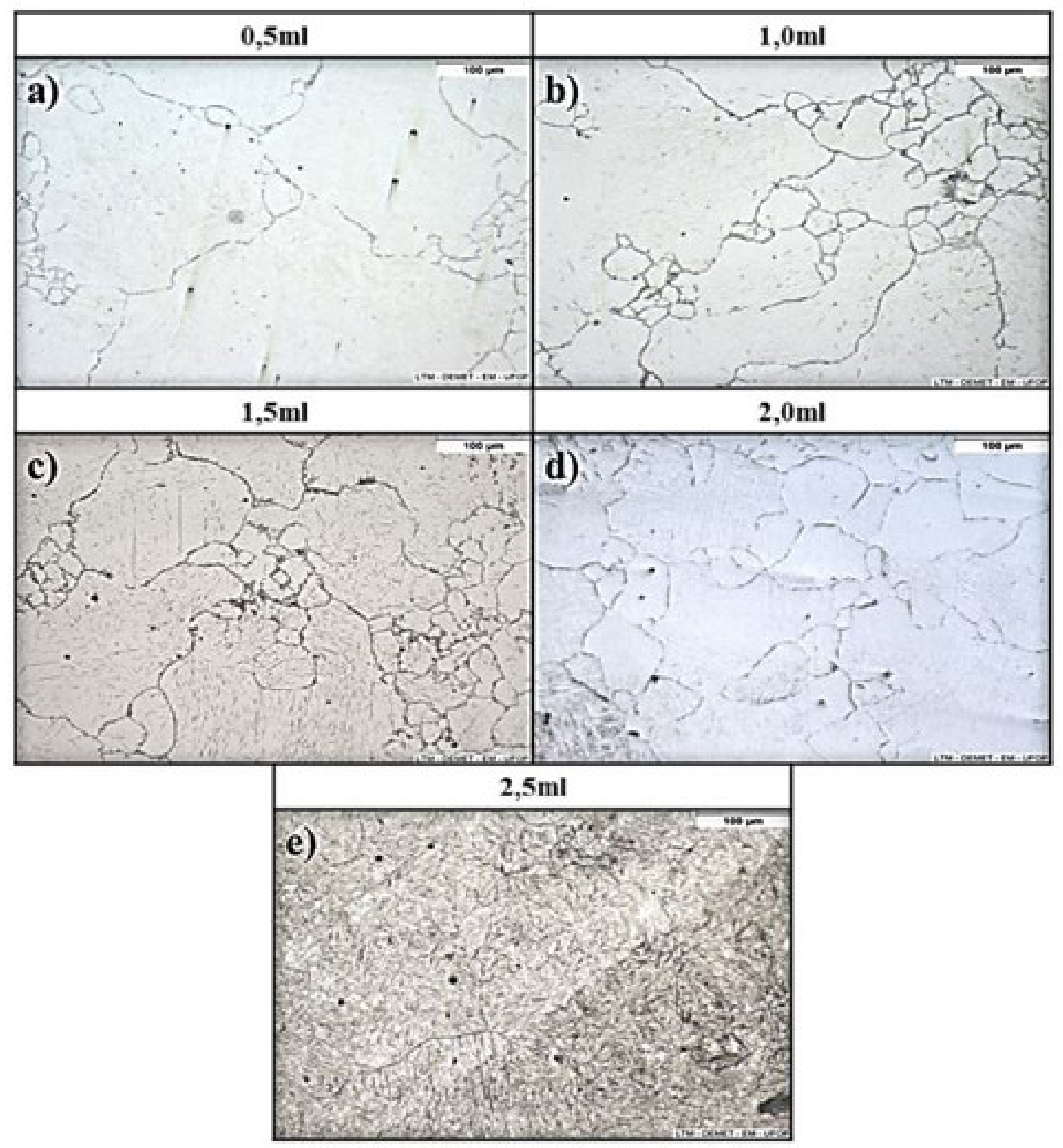

Figura 5. Micrografias resultantes do aço E com carbono equivalente igual a 0,69 atacado nas condições de: (a) $0,5 \mathrm{~mL}$ de $\mathrm{HCl}$ e tempo de $70 \mathrm{~s}$; (b) $1,0 \mathrm{~mL}$ de $\mathrm{HCl}$ e tempo de $90 \mathrm{~s}$; (c) $1,5 \mathrm{~mL}$ de $\mathrm{HCl}$ e tempo de $30 \mathrm{~s}$; (d) $2,0 \mathrm{~mL}$ de $\mathrm{HCl}$ e tempo de $40 \mathrm{~s}$; (e) $2,5 \mathrm{~mL}$ de $\mathrm{HCl}$ e tempo $10 \mathrm{~s}$.

motivos de tantos relatos de dificuldade para se adequar o reativo aos diferentes tipos de aços, como citado por alguns autores $[6,9,14]$ e evidenciado na introdução deste trabalho. Neste contexto, a Equação 2 foi proposta para se estimar o tempo de ataque de um aço com reativos à base de ácido pícrico à temperatura ambiente. Essa equação foi obtida por meio de uma regressão linear múltipla com coeficiente de correlação $\mathrm{R} 2=0,90$ e desvio máximo de $25 \mathrm{~s}$, onde t é o tempo de ataque (s), $\mathrm{HCl}$ é o volume de ácido clorídrico $(\mathrm{mL})$ e Ceq é o carbono equivalente do aço.

Apesar do bom coeficiente de correlação R2 $=0,90$, deve-se destacar que os p-valores encontrados para os parâmetros $\mathrm{Ceq}$ e $\mathrm{HCl}$ foram, respectivamente, 0,28 e 0,004. Estatisticamente, o p-valor, quando multiplicado por 100, indica em quanto por cento a equação estará errando caso a hipótese nula seja descartada. 


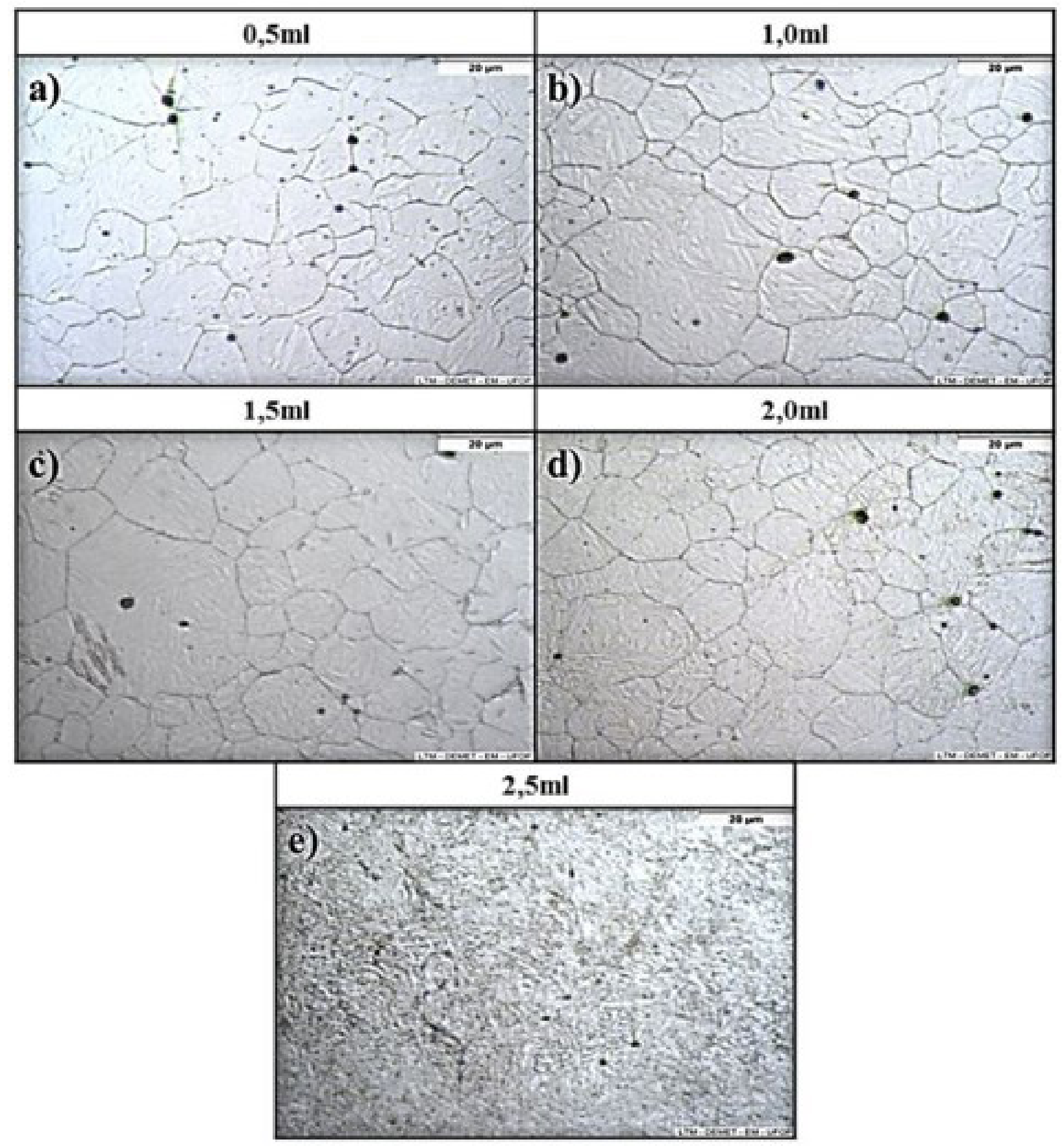

Figura 6. Micrografias resultantes do aço F com carbono equivalente igual a 0,83 atacado nas condições de: (a) $0,5 \mathrm{~mL}$ de $\mathrm{HCl}$ e tempo de $300 \mathrm{~s}$; (b) $1,0 \mathrm{~mL}$ de $\mathrm{HCl}$ e tempo de $180 \mathrm{~s}$; (c) $1,5 \mathrm{~mL}$ de $\mathrm{HCl}$ e tempo de $60 \mathrm{~s}$; (d) $2,0 \mathrm{~mL}$ de $\mathrm{HCl}$ e tempo de $50 \mathrm{~s}$; (e) $2,5 \mathrm{~mL}$ e tempo de $10 \mathrm{~s}$.

Tabela 2. Resumo das melhores condições de ataque para cada aço estudado

\begin{tabular}{cccc}
\hline Aço & C.E. & $\begin{array}{c}\text { Concentração de HCl mais } \\
\text { eficiente (m) }\end{array}$ & Tempo de ataque (s) \\
\hline A & 0,27 & 1,00 & 120 \\
B & 0,50 & 1,50 & 60 \\
C & 0,50 & 1,50 & 60 \\
D & 0,60 & 1,00 & 180 \\
E & 0,69 & 1,50 & 30 \\
F & 0,83 & 1,00 & 180 \\
G & 1,04 & 1,50 & 60 \\
\hline
\end{tabular}




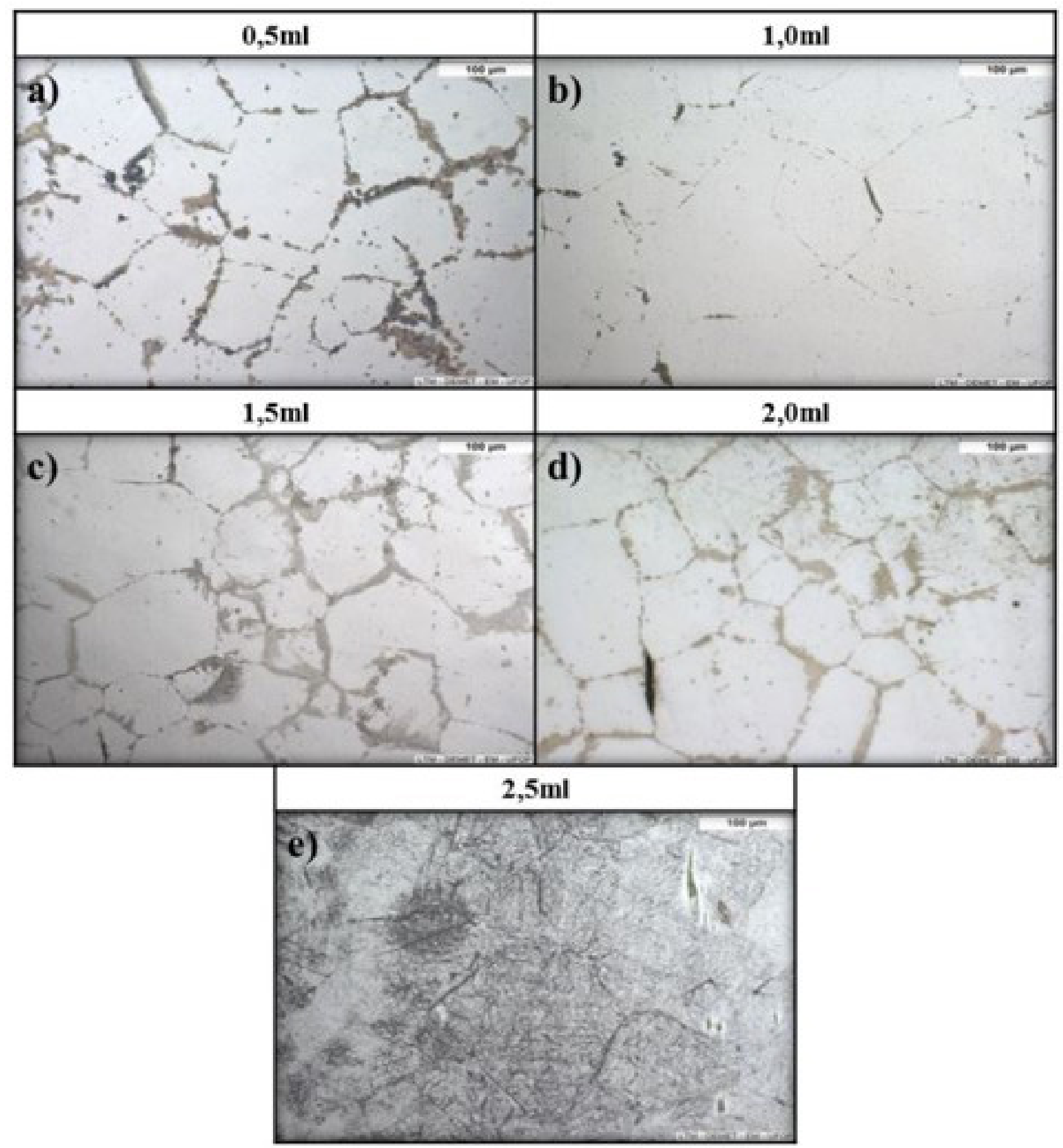

Figura 7. Micrografias resultantes do aço G com carbono equivalente igual a 1,04 atacado nas condições de: (a) $0,5 \mathrm{~mL}$ de $\mathrm{HCl}$ e tempo de 210 s; (b) $1,0 \mathrm{~mL}$ de $\mathrm{HCl}$ e tempo de $120 \mathrm{~s}$; (c) $1,5 \mathrm{~mL}$ de $\mathrm{HCl}$ e tempo de $60 \mathrm{~s}$; (d) $2,0 \mathrm{~mL}$ de $\mathrm{HCl}$ e tempo de $40 \mathrm{~s}$; (e) $2,5 \mathrm{~mL}$ de $\mathrm{HCl}$ e tempo de $10 \mathrm{~s}$.

Nesse contexto, é usual dizer que a influência de uma variável independente sobre a variável dependente é significativa se o p-valor assume um número menor do que 0,05 de forma que o nível de significância dos resultados seja de $95 \%$. Assim sendo, pode-se afirmar que o parâmetro com maior influência sobre o tempo de ataque, considerando o universo de dados utilizados, é a concentração de $\mathrm{HCl}$ utilizada no reativo.

$$
t=360+50 . C_{e q}-227 . H C l
$$

\section{Conclusões}

Determinou-se, para todos os aços estudados, uma condição ótima de ataque que consistiu no ajuste adequado 
da concentração de ácido clorídrico e do intervalo de tempo de ataque. Verificou-se que pequenas variações na concentração de ácido clorídrico $( \pm 0,5 \mathrm{~mL})$, ou do tempo de ataque ( \pm dezenas de segundos) para um mesmo aço pode levar ao sucesso ou insucesso da técnica. Nesse contexto, possivelmente essa seria a justificativa para inúmeros relatos de dificuldade de aplicação dessa técnica com sucesso, assim como para a publicação de resultados divergentes sobre a sua eficiência para uma mesma classe de aços.

Foi possível elaborar uma tabela de referência e propor uma equação de regressão linear múltipla que permite estimar, com base no carbono equivalente do aço e concentrações de
$\mathrm{HCl}$ entre 1,0mLe 1,5mL (faixa ótima), o tempo de ataque para revelação dos grãos austeníticos prévios em aços com características químicas semelhantes às dos estudados no presente trabalho. A concentração de $\mathrm{HCl}$ no reativo é o parâmetro estatisticamente relevante com maior influência sobre o tempo de ataque.

\section{Agradecimentos}

À Fundação Gorceix pelo auxílio em forma de bolsa de iniciação científica. Ao CNPq pela Bolsa de Produtividade em Pesquisa de um dos autores.

\section{Referências}

1 Kundu A, Chakraborti PC. Effect of austenite grain size and composition on matrix microstructure and properties of steel. Procedia Materials Science. 2014;5:1141-1147.

2 Kim JG, Enikeev NA, Abramova MM, Park BH, Valiev RZ, Kim HS. Effect of initial grain size on the microstructure and mechanical properties of high-pressure torsion processed twinning-induced plasticity steels. Materials Science and Engineering A. 2017;682:164-167.

3 Xueda L, Xiaoping MA, Subramanian SV, Chengjia S, Misra RDK. Influence of prior austenite grain size on martensite-austenite constituent and toughness in the heat affected zone of 700Mpa high strength linepipe steel. Materials Science and Engineering A. 2014;616:141-147.

4 Jiang T, Liu H, Sun J, Guo S, Liu Y. Effect of austenite grain size on transformation of nanobainite and its mechanical properties. Materials Science and Engineering A. 2016;666:207-213.

5 Ferdian D, Ariati M, Norman A. Method for detecting austenite grains in low-carbon steel after hot deformation. Metal Science and Heat Treatment. 2013;5:54-58.

6 García de Andrés C, Bartolomé MJ, Capdevila C, San Martín D, Caballero FG, Lopéz V. Metallographic techniques for the determination of the austenite grain size in médium-carbon microalloyed steels. Materials Characterization. 2001;46:389-398.

7 García de Andrés C, Caballero FG, Capdevila C, San Martín D. Revealing austenite grain boundaries by termal etching: advantages and disadvantages. Materials Characterization. 2003;49:121-127.

8 Palizdar Y, San Martin D, Ward M, Cochrane RC, Brydson R, Scott AJ. Observation of thermally etched grain boundaries with the FIB/TEM technique. Materials Characterization. 2013;84:28-33.

9 Faria G, Cardoso R, Moreira P. Development of an oxidation method for prior austenite grain boundary revelation. Metallography. Microstructure and Analysis. 2018;7:533-541.

10 Sha QY, Huang GJ, Guan J, Ma XJ, Li DH. A new route for identification of precipitates on austenite grain boundary in na Nb-V-Ti microalloyed steel. Journal of Iron and Steel Research International. 2011;18(8):53-57.

11 Li YJ, Ponge D, Choi P, Raabe D. Segregation of boron at prior austenite grain boundaries in a quenched martensitic steel studied by atom probe tomograpy. Scripta Materialia. 2015;96:13-16.

12 Nasim M, Edwards BC, Wilson EA. A study of grain boundary embrittlement in na Fe-8\%Mn alloy. Materials Science and Engineering A. 2000;281:56-67.

13 Zhang L, Guo DC. A general etchant for revealing prior-austenite grain boundaries in steels. Materials Characterization. 1993;30(4):299-302.

14 Reiter J, Bernhard C, Presslinger B. Austenite grain size in the continuous casting process: mettalographic methods and evaluation. Materials Characterization. 2008;59:737-746.

15 Ozaki H, Naiman J, Masubuchi K. A study of hydrogen cracking in underwater steel welds. Welding Journal. 1977;8:231.

16 American Society for Testing and Materials. ASTM E3-11: standard guide for preparation of metallographic specimens. West Conshohocken: ASTM International; 2011. 
Avaliação da formulação de reativos à base de ácido pícrico visando a revelação do grão austenítico prévio em diferentes tipos de aços

17 Souza SS, Moreira PS, Faria GL. Austenitizing temperature and cooling rate effects on the martensitic transformation in a microalloyed-steel. Materials Research. 2020;23(1)

18 Miyahara VTP. Avaliação das propriedades mecânicas e da microestrutura de aços dissimilares ABNT 8620 e ABNT 6655 LN 28 soldados com arco pulsado com diferentes temperaturas de pré-aquecimento e tipos de tecimento [dissertação]. Bauru: UNESP; 2008.

Recebido em: 11 Jun. 2020

Aceito em: 28 Set. 2020 